\title{
10
}

\section{INSIGHTS - Integrated simulation game for a comprehensive redesign of production systems}

G. Zülch, U. Jonsson, A. Rinn

ifab - Institute of Human and Industrial Engineering, Kaiserstr. 12, D-76128 Karlsruhe, Tel. +49 (0)72160842 50,Fax+49 (0)7216945 57, e-mail: gert.zuelch@mach.unikarlsruhe.de

\begin{abstract}
The integrated simulation game for planning and reorganizing production systems has been developed at the ifab-institute in order to engage the awareness of the players for actual problems in real production systems. During the planning game the participants have to act on operative level as well as on strategic issues. First they have to plan and control the production of an existing assembly system for producing bicycles in planning teams. The system is modeled using the simulation tool FEMOS. Running the factory the teams are going to detect weak points inside the existing system. This experience is the basis for reorganizing the assembly system afterwards. The paper consists of demonstrating the principle structure of the planning game, the material used as well as an illustration of different planning results obtained by playing the game with students and professionals.
\end{abstract}

\section{Keywords}

Simulation game, production planning and control, redesign of production systems, computer based 


\section{INTRODUCTION}

The game being explained in the following is called INSIGHTS, which means integrated simulation game for a comprehensive redesign of production systems. It was developed at the ifab-institute during the CAESAR project which is part of the programme LEONARDO da VINCI of the European Commission. The objective of the game is to engage the awareness of industrial managers for actual problems in real production systems. These problems are caused by strong market changes and an increasing competition on the market. So the industrial companies are forced to adapt their activities on operative as well as on strategic level. Therefore, the participants have to act on operative and strategic issues during the planning game concerning an assembly system for bicycles.

This application field has been chosen due to the well known product with an adequate product complexity. Because of the familiarity of bicycles and their components, the participants are not forced to spend too much effort in analyzing products and their bill of materials. On this basis the participants can fully concentrate on the organizational problems inside the production system which is modeled using the simulation tool FEMOS (refer to Zülch, Grobel 1996). By running the factory in a simulation model, the participants have the opportunity to recognize the impact of their planning solutions on the dynamic behavior of the production system.

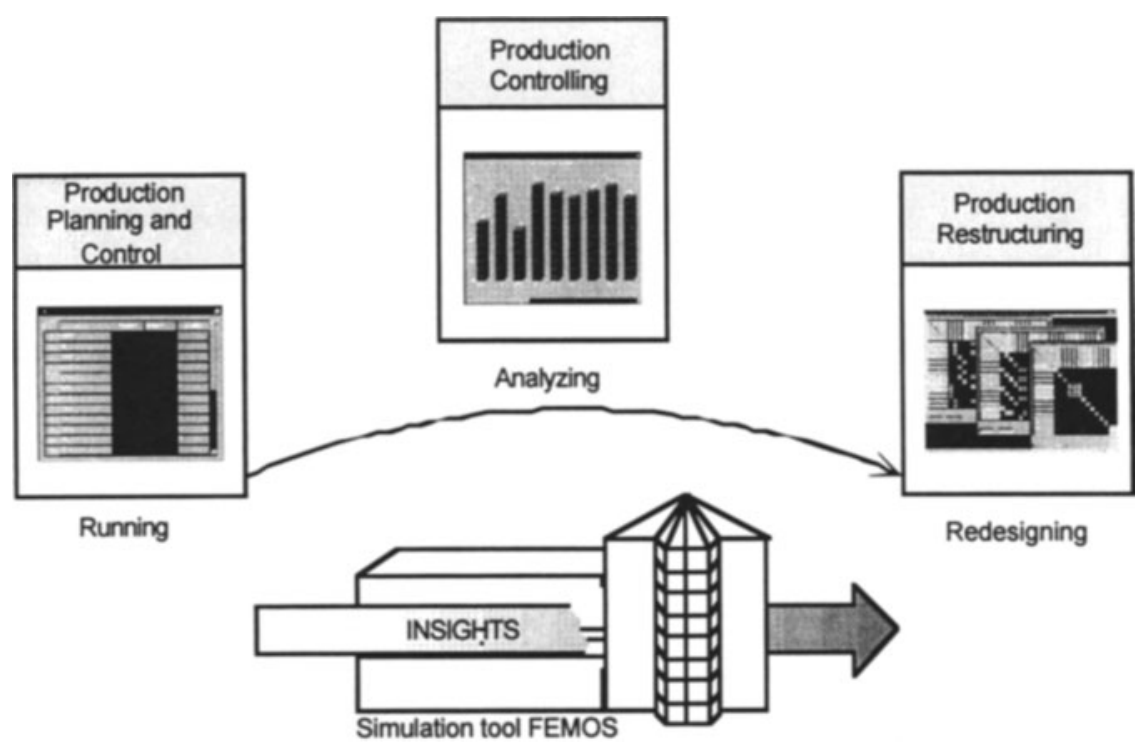

Figure 1: Structure of the planning game

The global target of the planning game is to allow a better understanding of running a factory, analyzing the existing situation and finding solutions for a better performance of the production system by reengineering it. 
Therefore, the planning game is separated into three different modules, namely the production planning and control (PPC), the production controlling and the redesign of production systems (cf. figure 1). These modules deal with adequate problems in order to improve the understanding and knowledge concerning production systems in general. The modules represent different aspects in production management which can be investigated independently. This is the basis for an optimal adaptation of the seminar to the needs of the participants.

By teaching students and professionals in production management and applying simulation supported seminars during several years, these topics have been proved as very important for a good understanding of reengineering and its future application by the participants.

The modules are defined as single running modules. This means every part is running on its own and can be chosen as stand-alone seminar. Each module is split into a theoretical lecture and practical planning work. This work is performed within teams of 3 to 4 participants.

As computer platform standard Personal Computers were chosen in order to design the planning game as flexible as possible. Due to the broad installations of the graphical operating system Microsoft Windows, the simulation program is running under Windows95. On this basis the seminar can easily run in every company or university without high preparation effort.

\section{PRODUCTION PLANNING}

The first module in the normal sequence of the planning game is running a simulated bicycle factory by means of production planning and control. The objective of this part of the seminar is to confront the participants with standard problems in running a factory as they occur in real life. In order to recover the present knowledge and to balance the relevant learning, the participants follow a short lecture of production planning and control theory. Parts of the lecture are on the one side general logistical aspects such as lead time reduction or increase of utilization and on the other side monetary criteria of productivity. Furthermore, the interdependencies of the different logistical aspects and the most common strategies of how to achieve the expected goals are presented and discussed. This lecture is limited to the practical needs of reality as well as of the planning game in order to keep the theoretical part of the seminar as moderate as possible.

After the theoretical part the participants are faced with the concrete planning case of the bicycle assembly. Therefore, they follow an introduction by the lecturer concerning the principal structure of the bicycle assembly and the products. During this introduction the different areas of bicycle assembly e.g. the wheel assembly, the pre- and final assembly etc. and the assigned tools and personnel are presented. Furthermore, the participants learn the details of the final products, the three bicycle types standard, trekking and mountain bike, and their components. During this introduction various information packages, including the necessary information about the processes, the processing times and their precedence relations are made available. Besides the process documentation, descriptions about the parts and the parts structure of the different products and components are 
disseminated to the participants. Additionally, all information about the existing functional organization of the assembly line is given to every group. During this part of the seminar, the participants are not allowed to change the organizational structure of the assembly.

After the analysis of the disseminated information material, the participants are faced with a specific demand for the three types of bicycles for the present period as well as with forecasts for the following periods. On this basis the participants have to determine the production orders for finished and semi-finished products considering their lot sizes and release times. In addition, they have to calculate the needs of purchase parts in linkage with the determined production orders (cf. figure 2). Due to some multiple use of purchase parts and components, the demands for the three bicycle types can not be analyzed separately. For example, the same spokes are used in all bikes and further on, the same wheels are used in trekking and mountain bikes. Handling this simulation the awareness of the participants is improved for this kind of problems which are occurring in several other production areas. Furthermore, the purchase is restricted by some predefined rules concerning the delivery times of economical normal and expensive urgent orders and their respective standard deviations. Also quantity discounts are given by the suppliers of each purchase part exceeding a specific number.

Besides the planning of production and purchase, the capacity adjustment on a static basis has to be done by the teams. This is prepared by calculating the expected capacity needs and comparing the results with the existing resources. The adjustment can be done by using overtime hours or introducing additional shifts for specific workplaces.

Afterwards, the teams run the simulation tool for achieving the results of their planning solution by analyzing the dynamic behavior on the PC. For example, the participants can see the difference between their statical capacity calculation and the dynamical utilization in the simulation run. Also, the success in planning the purchase and the production orders is shown by the simulation run.

Depending on the duration of the seminar, the participants have to plan a certain number of periods which equal to one week in the simulation run. Moderate numbers of periods are three to five. Less than three periods means the participants do not have the chance to modify an ineffective strategy and after five periods the additional educational gain tends to decrease.

During this PPC-module of the seminar, simulation is used for demonstrating the behavior of a real production system by running it on the calculated data of the teams. Mistakes which occur during the planning phase and are detected in the simulation run should be corrected during the following planning periods similar to reality. This means the participants are not allowed to correct the planning data of the actual planning period and repeat the simulation run for the same period. 


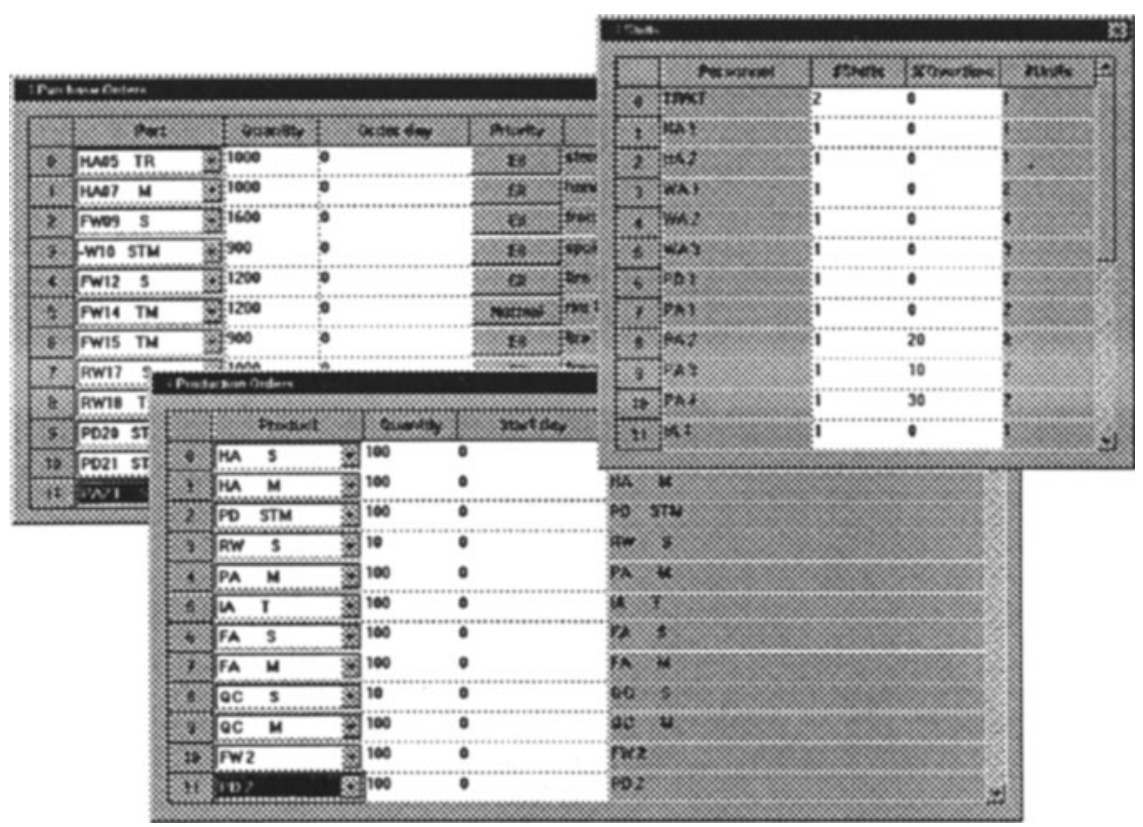

Figure 2: Input masks for the planning data

\section{PRODUCTION CONTROLLING}

In order to identify potentials for improvement, performance evaluation of production systems is a topic of growing importance to companies. Therefore, this next part has been added to the seminar in order to introduce the participants to the theory and practice of performance measurement.

After running the assembly line for a few periods, the participants learn more and more to run the bicycle assembly with the given information of the simulation runs. During the PPC-part the evaluation information has been limited to a defined level in order to not confuse the participants. The experience gained during planning the production leads to an increasing demand of more detailed information concerning the tracing of the simulation behavior and the afterwards evaluation on different points of view. This is the initial point for instructing the participants the theory of production controlling. Therefore, the production controlling module consists of three aspects:

- statical analysis of the existing production structure,

- tracing the simulation run and

- analysis of the simulation results.

All aspects concentrate on logistical and monetary evaluation of production systems. The statical analysis deals with performance indicators which describe the 
organizational structure (e.g. number of functions assigned to the personnel), the parts structure (e.g. the size of the parts tree structure) and also the precedence structure of processes (e.g. number of processes which can be operated in parallel in relation to the total number of processes). The presented indicators provide a condensed view of the existing system and can by applied e.g. for controlling the existing system or for benchmarking with other production systems.

Besides the statical evaluation of the production system, the participants learn how simulation can be applied for a dynamical analysis during and after the simulation run. During the simulation run, the system provides several possibilities of tracing the operated processes and the involved resources of the production system. Therefore, e.g. detailed representations of work places, personnel, stocks or waiting queues can be selected by the participants and visualized on-line during simulation.

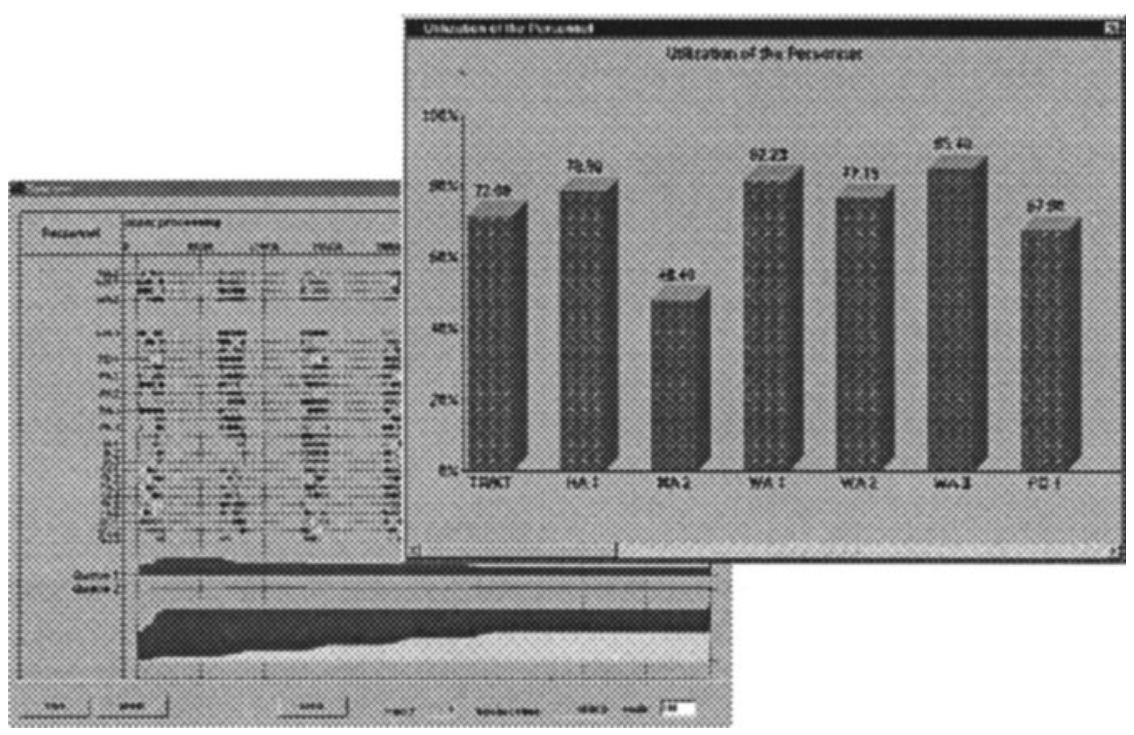

Figure 3: Tracing simulation and dynamical analysis of the production system

After tracing the simulation run a wide range of performance indicators for the analysis of the simulation data is at the disposal of the participants. Logistical aspects e.g. the utilization of the individual resources can be investigated as well as costs for machines or personnel up to total activity based costing indicators by using the evaluation tool set of the simulation system (refer to Zülch, Brinkmeier 1996). On this basis, the participants get an impression of the interdependencies between different logistical and monetary goals and how to achieve specific objectives with different planning and control strategies. Just-in-time delivery, maximization of utilization or short lead times are examples which can be analyzed. 
While simulating the starting solution with the existing organizational structure and applying the indicators of the evaluation tool, weak points of the starting solution are detected and ideas for potential improvements are developed by the participants. This is the initial point for the third part of the seminar concentrating on production reengineering.

\section{REDESIGN OF THE PRODUCTION SYSTEM}

After getting an in-depth look into the structure and the problems of the existing bicycle factory through the planning and the controlling part of the game, the participants get the opportunity to improve the situation substantially. The main objective of this part is to face the participants with possibilities and requirements of new forms of work organization, e.g. segmentation, group work, outsourcing etc. The scenario of the game is, that the market demand will increase about $25 \%$ and that the existing structure is not able to cope with this situation. Therefore, each team has to design a new work structure which improves the existing situation and is able to satisfy the new demands.

An important point is the evaluation of the solutions that will be worked out by the different planning teams. In order to consider not only monetary but also nonmonetary criteria, a so-called dual evaluation is used (refer to Grob, Haffner 1982). While the monetary evaluation is based on an investment calculation, the nonmonetary criteria are evaluated by means of benefit analysis. Thereby, especially those criteria which are difficult to quantify (e.g. quality improvement, worker's satisfaction) can be taken into consideration.

In the initial situation, the work structure is functional oriented and divided into several assembly blocks (e.g. handle bar assembly, pre-assembly, quality control etc.). In order to give a starting point to the planning teams, they first have to decide whether to introduce a product-oriented segmentation or group work structures instead of the initial assembly lines. This decision must be taken for every assembly block separately. Furthermore, it is possible to join the assembly blocks into greater units. For example, it is possible to define three large production segments, one for each bicycle type, which cover the whole production process. The choice of a principle work structure is intended to give a frame to the following planning tasks. Further adjustments of the structure are possible and due to the generic definition of the underpinning simulation system, virtually any form of work structure can be designed and simulated.

Usually, the next step for the redesign of the production system is the analysis of the work flow. The flow of production orders through the system is planned based on activity networks (refer to Zülch, Brinkmeier 1996) as shown in figure 4. These networks mainly describe the technological precedence between the assembly steps as well as their work content. Both information are essential for the planning procedure. Based on these activity networks, a first approach for the assignment of assembly steps to work places can be made. 


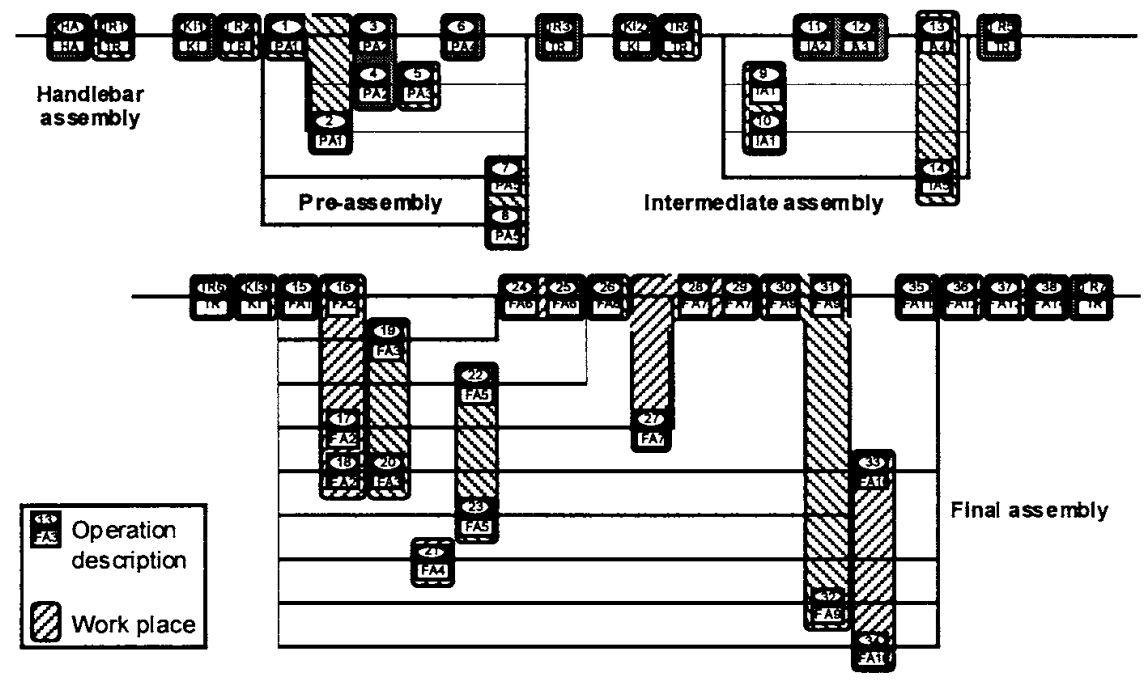

Figure 4: Planning of the work flow

The work structure itself is modeled through three relations, which are represented by three input matrixes (cf. figure 5):

\section{Feasibility:}

This relation between assembly operations and work places describes, at which work places each individual operation can be performed. For example, in a production line usually every assembly step is assigned to its own work place. By contrast, in a group work structure many operations share the same work place. If more than one work place is assigned to an operation, a priority must be defined.

\section{Competence:}

By this relation the personnel is assigned to the work places. Therefore, it defines which person belongs to which assembly unit (segment or group). Furthermore, it is possible to share person between units. In this case, it is necessary to define a priority ranking for the assembly units.

\section{Ability:}

The third relation between personnel and operations describes, which person is able to perform a certain assembly task. Thereby, it defines the qualification structure of the labor force. The assembly tasks are grouped into several qualification levels. By assigning a number of tasks of the same qualification level to a person, job enlargement can be achieved. The assignment of tasks with higher requirements to a person leads to job enrichment. Both measurements result in qualification costs and possibly also in higher wage rates, so the planning teams have to evaluate carefully, whether these additional costs are justified e.g. by a higher productivity or other advantages, such as shorter lead times. 


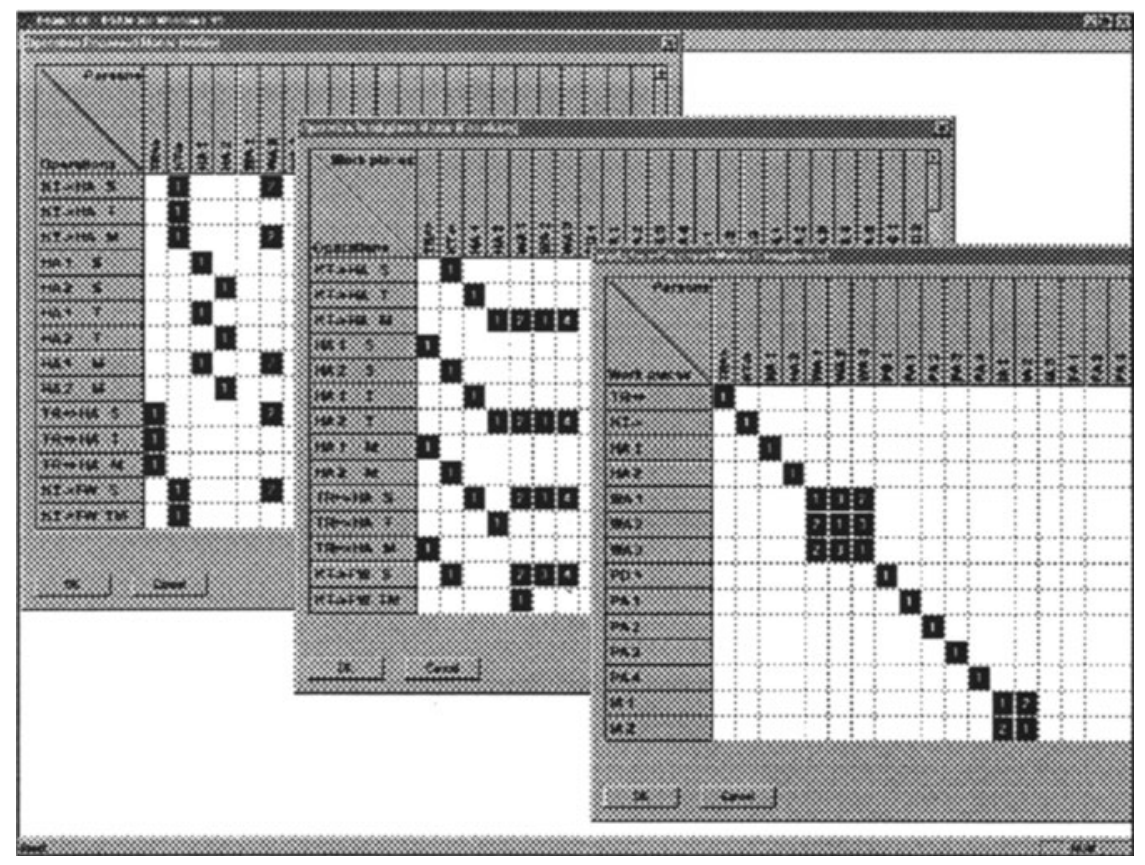

Figure 5: Modeling of work structures

Another issue of work structuring in the planning game is the outsourcing of components. Figure 6 shows the outsourcing of the wheel production and its effects on the bill of material. By outsourcing specific components, the planning teams can dramatically simplify their structure but on the other side they have to deal with new problems caused by the dependency from the supplier. The process of outsourcing starts with negotiations about the price between the planning team and the supplier (represented by the lecturer). For this, a good knowledge about the production costs of the involved components is required. The teams have to decide whether and for which components outsourcing is economically sensible. After taking the decision for outsourcing, the simulation model is adapted. The related components and production facilities are removed from the system and the outsourced component is transferred into a usual purchase item. This means, it has a purchase price and a certain distribution that describes the delivery characteristics of the supplier. 


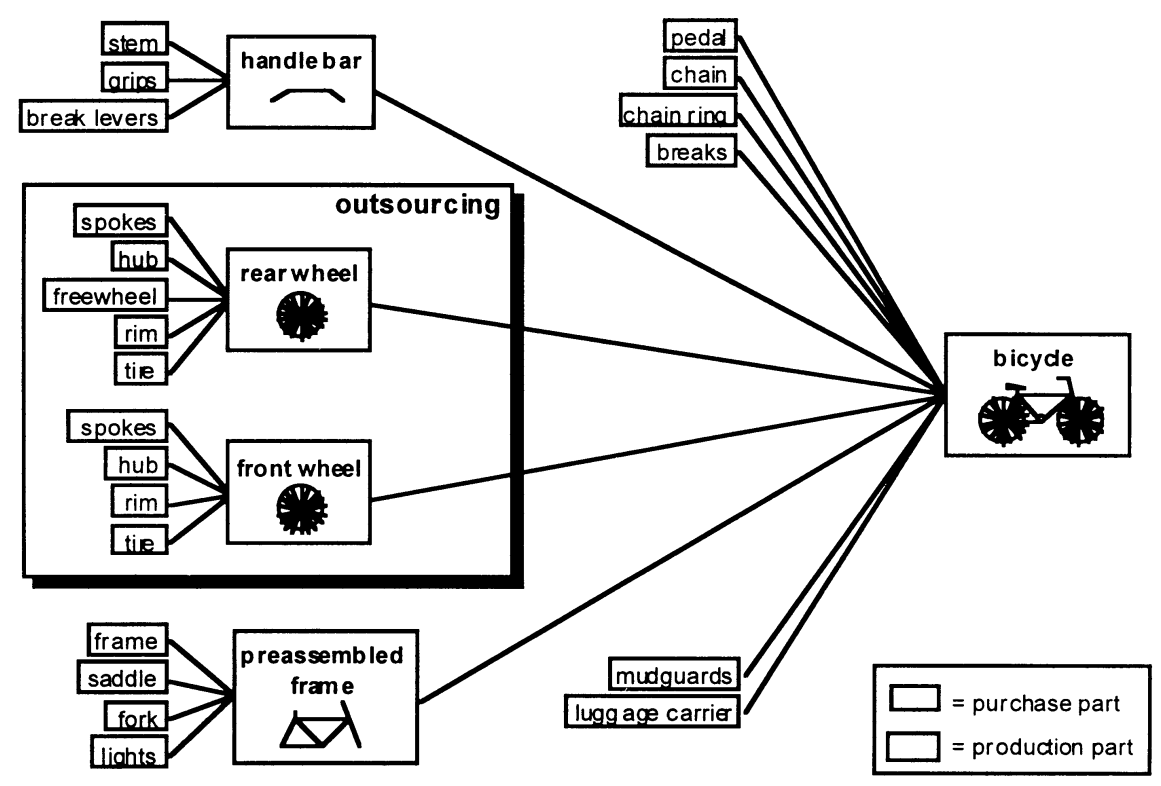

Figure 6: Outsourcing of components

Besides the basic modeling aspects, the planning teams also have to develop a layout in order to visualize their new work structure. Especially those aspects, which are not covered by the simulation, can be visualized. This layout shall include

- design of work places,

- recreation areas,

- layout of the material flow,

- security issues (e.g. emergency exits) and

- other human aspects.

After the new work structures have been worked out, the planning teams model their individual solutions using the simulation program FEMOS. Thus, they have the opportunity to perform several simulation cycles in order to incrementally improve their solution. This improvement is based on the various monitoring and controlling capabilities of the simulation program which already have been introduced during the second part of the seminar.

When the solutions have been finished, they are finally evaluated based on the criteria which have been already fixed at the beginning of this seminar part. While the monetary evaluation is done through a simplified investment calculation, the evaluation of the non-monetary criteria is based on a benefit analysis. Thereby, the criteria are weighted against each other and the degree of fulfillment is determined 
for every criteria. Based on this, a so-called work system's value is calculated which quantifies the non-monetary benefit of the solution. Both, the monetary and the non-monetary value are then used simultaneously to evaluate the solutions of the planning teams against each other.

\section{PRESENTATION OF THE SOLUTIONS}

The last step of the seminar is the presentation of the different solutions. Therefore, the teams have to prepare a number of flip charts and to present their ideas, strategies and results in front of a fictitious "board of management". The presentation is usually separated into the production planning and control and the redesign part. This means the groups have to prepare separate presentations for these two seminar parts. Usually, the presentation is directly after the relevant seminar module. On this basis, all teams have the chance to see the strategies and results of the other teams.

This part of the seminar is to give the participants the experience of explaining their results to the management and other responsible persons which may not be in favor of their solution and have to be convinced. Students as well as professionals shall learn how to present and defend their ideas concerning logistical and monetary aspects.

\section{TARGET GROUPS}

The seminar is designed to fit the needs of educating students in a practical way as well as teaching professionals in order to commit them to detect existing problems in their own production sites. Students learn the principle theory of the different topics and furthermore, they gain some experience in applying the theory in a practical planning environment. Due to the theoretical orientation of studies at universities students have a real chance to run a simulated factory on their own and to apply own ideas for improvements. The experience has shown that students are highly motivated in following the planning game and they still have this planning game in mind years after finishing their studies.

Playing the game with professionals the chance is given to reflect on existing knowledge and experience. The participants can apply some ideas they were not able to use before in reality. Besides the theoretical content, all participants learn in some hours how to handle and run a simulation tool. During the redesign module, the participants are able to apply this new knowledge in about half a day for designing a probably fully new production system. After one day they are already able to run their new and own designed production system on the PC. Very often, this rapid realization period is surprising to professionals who are not usually using simulation tools. 


\section{OVERALL EXPERIENCES IN RUNNING THE DIFFERENT MODULES}

As described in the previous chapters the seminar is composed of three modules with a preferred sequence. But due to its modularity the single parts of the seminar can be selected and used as stand-alone modules depending on the target group and the objectives of the seminar. Therefore, the introduction of the bicycle assembly presented in the production planning and control part has to be moved to the chosen module. Furthermore, the span of the theoretical lecture can be easily adapted to the initial skills of the participants.

Playing the seminar with students and professionals time restriction is another major criteria. Mainly small and medium sized companies are not able to leave their employees for a whole week of continuing studies because of daily work. Besides this, leaving a larger group of experts for several days is of major importance for the management. Therefore, single modules of the seminar can be organized starting with approximately two days for the production planning and control module or the redesign module. The duration can be enlarged by extending each module and combining it with the other segments up to five or six days. This duration usually fits to compact lectures at universities.

During the planning game itself, the participants are fully free to apply any support they have at their disposal. Therefore, spreadsheet software is very often used to fulfill the planning and reengineering tasks. In order to perform all tasks during the limited time of each module the teams have to organize themselves by splitting the work within the team. Furtheron, playing the seminar with a few teams in parallel, the speed in operating planning tasks is usually different which means a difference of sometimes one hour. The lecturer has to manage this problem with additional tasks to the faster planning teams in order to balance the speed of the groups.

\section{SUMMARY}

During the planning game the teams are learning very fast how to apply the simulation program as an adequate tool for analyzing and redesigning existing production systems. Following the seminar the participants are gaining an impression of how simulation can be utilized for operative and strategic investigations of own practical problems. The span of these problems is covering different planning and control strategies as well as organizational changes to group work or segmented work structures.

The actual configuration of the simulation aided planning game is resulting from the experience in running it over some years. The three different modules have been established as an ideal composition to enhance the awareness of real problems in the area of production planning and control, production controlling and redesigning existing systems. Additionally, participants are instructed in using simulation tools as an appropriate analysis tool in business process reengineering. 


\section{REFERENCES}

Grob,R.; Haffner, H.: Planungsleitlinien Arbeitsstrukturierung. Berlin, Munich: Siemens AG, 1982.

Zülch, Gert; Brinkmeier, Bernd: Simulation Aided Planning of Work Structures. In: Simulation Games and Learning in Production Management. Edt.: Riis, Jens O. London et al.: Chapman \& Hall, 1995, 91-104.

Zülch, Gert; Brinkmeier, Bernd; Heel, Jochen: Lernen bei der Organisationsentwicklung durch den Einsatz von Simulationsverfahren. In: Lernende Unternehmen. Edt.: Bullinger, Hans-Jörg. Stuttgart: SchäfferPoeschel Verlag, 1996, 199-232.

Zülch, Gert; Brinkmeier, Bernd: Simulation of Activity Costs for the Reengineering of Production Systems. In: Ninth International Seminar on Production Economics. Igls, 19.-23.2.1996 Pre-Prints, Vol 3, 1996, 229-245. Zülch, Gert; Grobel, Thomas: Shaping the organization of order processing with the simulation tool FEMOS. In: International Journal of Production Economics. Amsterdam, 42 (1996) 46-47, 254-260.

\section{BIOGRAPHY}

\section{Gert Zülch}

Since 1985 he is head of the ifab-institute of Human and Industrial Engineering of the University of Karlsruhe. Previously he served as head of the Department for Work Structuring within the Central Department for Research and Technology of SIEMENS (Munich) and Chief Engineer of the Research Institute for Rationalization (FIR) at the University of Technology of Aachen. His research activities include ergonomics of communication in industrial applications, computer-aided design of manual work places, computer applications in time studies, simulation of organization and qualification of personnel in industrial workshops, structuring of the departmental organization of industrial enterprises and strategies of production planning and control.

\section{Uwe Jonsson}

He studied Computer Science at the University of Karlsruhe and works as research assistant at the ifab-Institute since 1993. He has been involved in several simulation based studies and is responsible for the development of the simulation tool FEMOS which has been applied in a large number of research and industrial projects. His scientific working fields are production planning and control, enterprise modeling and object-oriented simulation techniques.

\section{Andreas Rinn}

He studied Industrial Engineering at the University of Karlsruhe. During his studies he spent one semester at the Graduate School of Industrial Engineering and Management Science at the Technical University of Eindhoven. Afterwards he started his work as research assistant at the ifab-Institute. His main working fields are production management and enterprise modeling. He has been involved in several simulation based studies in national and international projects. 